Rapid Report

\title{
Hepatic lipase mRNA is expressed in rat and human steroidogenic organs
}

\author{
Adrie J.M. Verhoeven *, Hans Jansen \\ Department of Biochemistry, Erasmus University Rotterdam, Postbox 1738, 3000 DR Rotterdam, The Netherlands
}

(Received 4 November 1993)

\begin{abstract}
Rat and human steroidogenic organs contain an enzyme activity that is indistinguishable from hepatic lipase present in liver. Using primers that recognize exons 5 and 8 of the rat and human $\mathrm{HL}$ gene, a 596-bp product was found by RT-PCR in rat liver, adrenal, ovaries and testes, but not in heart and kidney. A similar product was also observed with human hyperplastic adrenocortical tissue. Identity of this product with part of the HL cDNA was confirmed by restriction mapping and internal re-amplification. Our results indicate that the HL gene is transcribed in steroidogenic tissues that also contain HL protein.
\end{abstract}

Key words: Hepatic triacylglycerol lipase; Adrenal; Ovary; Testis; Cushing's disease; (Human); (Rat)

Hepatic lipase (HL; EC 3.1.1.34) is present in the liver of most vertebrates at the endothelial lining of blood sinusoids [1]. The enzyme plays a central role in lipoprotein metabolism. Notably, HL is shown to facilitate uptake by liver cells of cholesterol from high-density lipoproteins (HDL) [1-3]. A highly similar enzyme activity (liver-type lipase) has been detected in rat, human, hamster and bovine adrenal cortex [4-6] and in rat ovaries $[5,7]$. At least in the rat, these organs depend largely on $\mathrm{HDL}$ cholesterol as the source for steroidogenesis [8,9]. Immunologically and kinetically, the liver-type lipases are indistinguishable from HL present in liver [10,11]. In addition, the adrenal lipase has a peptide map which is similar to that of hepatic lipase from liver [12]. These observations strongly suggest that these lipases represent a single gene product.

The origin of the liver-type lipases in the steroidogenic organs remains unknown. Attempts to detect local de novo synthesis in unstimulated rat adrenals and highly luteinized ovaries have been unsuccessful

\footnotetext{
* Corresponding author. Fax: +31104360615. Abbreviations: bp, base pairs; HDL, high-density lipoproteins; gww, gram wet weight; HCG, human chorionic gonadotrophin; HL, hepatic lipase; mRNA, messenger RNA; nt, nucleotide; PCR, polymerase chain reaction; PMS, pregnant mare serum; RT, reverse transcription.
}

$[12,13]$. HL mRNA has never been observed in adrenals and ovaries by classical Northern blotting [12-15], nor in ovaries by application of the polymerase chain reaction [13]. This led to the hypothesis that the liver-type lipases are synthesized exclusively in the liver, and are subsequently transported to and sequestered in the steroidogenic organs. In normal rat and human plasma, however, hepatic lipase is hardly detectable [16]. We therefore decided to reinvestigate the possibility of local synthesis, by studying the expression of HL mRNA in steroidogenic organs by RT-PCR.

Total RNA was isolated by the method of Chomczynski and Sacchi [17]. Adrenals, testes, liver, heart and kidney were rapidly dissected from male Wistar rats (250-300 g). Ovaries were obtained from immature rats treated for various times with the gonadotrophins PMS and HCG [18]. Human hyperplastic adrenals were obtained from two patients suffering from Cushing's disease who were subjected to bilateral adrenalectomy. Total RNA was also isolated from the human hepatoma cell line HepG2 and umbilical vein endothelial cells (passage 5), starting from one T150 flask (Nunc, Roskilde, Denmark) of confluent cells each. RNA concentrations were determined by spectrophotometry at $260 \mathrm{~nm}$ [19]. The quality of all RNA preparations was similar as judged from the pattern of ribosomal RNA after gel-electrophoresis [19].

RT-PCR was performed in a single tube, using the 
RNA-PCR kit from Perkin Elmer Cetus. Routinely, 1 $\mu \mathrm{g}$ of total RNA was reverse-transcribed using oligo(dT $)_{16}$. Amplification was performed in 35 cycles of, successively, $1 \mathrm{~min} 95^{\circ} \mathrm{C}, 1 \mathrm{~min} 55^{\circ} \mathrm{C}$ and $1 \mathrm{~min}$ $72^{\circ} \mathrm{C}$, using the oligonucleotides $\mathrm{HL}-1$ ( $5^{\prime}$-GTG GGC ATC AAA CAG CCC-3', nt 697-714) and HL-2 (5'CAG ACA TTG GCC CAC ACT G-3', nt 1292-1274; numbering according to the rat CDNA sequence, see Ref. 14) as forward and reverse primers, respectively. These oligonucleotides recognize both the rat and human HL sequence in exon 5 and 8, respectively [14,2023]. Possible contamination with DNA was assessed in parallel incubations in which reverse transcriptase was omitted. A no-template control was included in each experiment. PCR products were analyzed by electrophoresis in a 3\% agarose gel (Nusieve: Seakem = 3:1; FMC Bioproducts, Vallensbæk Strand, Denmark).

For re-amplification, the PCR mixture was diluted 10000 -fold into a fresh one, and PCR was performed for 25 cycles using the primers HL-2 and HL-3 ( $5^{\prime}$-CGG GGG CTC CTT CCA GCC TGG-3', nt 741-761). For restriction enzyme analysis, $15 \mu \mathrm{l}$-aliquots were diluted into $100 \mu 1$ of the appropriate buffer; after overnight digestion, the DNA was collected by ethanol precipitation. Restriction enzymes and DNA molecular weight markers were from Boehringer-Mannheim, Germany.

Lipase activity assays, immunoinhibition assays and chromatography on Sepharose-heparin were performed as described previously [4,10]. Protein was determined by the Lowry assay [24] using bovine serum albumin as a standard.

RT-PCR on total RNA isolated from rat liver yielded one major product with the expected size of 596-bp (Fig. 1A). Using the same conditions, a similarly sized product was generated with RNA prepared from whole adrenals. This result was not duc to contamination with DNA, as amplification of the 596-bp product was not seen in the absence of reverse transcriptase (-RT control). In contrast, RT-PCR on heart and kidney RNA using $\mathrm{HL}$-specific oligonucleotides remained negative (Fig. 1A), although all RNA preparations were of similar quality and readily allowed for the amplification of full-length mRNA for glyceraldehyde 3-phosphate dehydrogenase (not shown). A 596-bp product was also generated with total RNA from stimulated rat ovaries and testes (Fig. 1B).

Identity of the 596-bp PCR products obtained from adrenal and ovarian RNA with part of the HL cDNA was confirmed by restriction mapping and internal re-amplification. Digestion of the products from adrenals, ovaries and liver with $B c l \mathrm{I}$ and $P s t \mathrm{I}$ resulted in the predicted fragments of 545-bp, and of 400 and 196-bp, respectively (Fig. 2A and B). An identical pattern was also obtained upon partial digestion with Sau 3A; besides the expected products of complete digestion, three extra bands of 377,249 and 219-bp
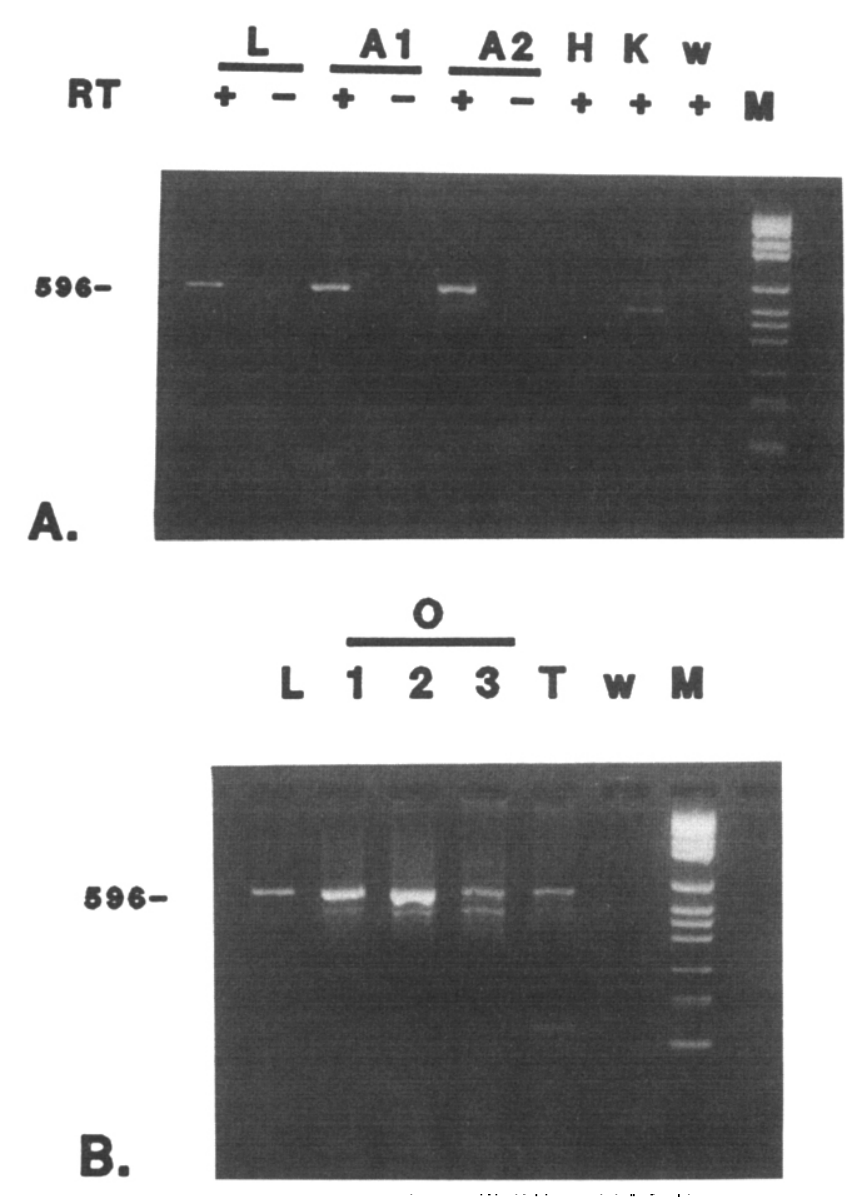

Fig. 1. Detection of HL mRNA in rat adrenals (A), ovaries and testes (B). RT-PCR was performed with $1 \mathrm{ng}$ of liver RNA (lane L), or with $1 \mu \mathrm{g}$ of total RNA isolated from two independent adrenal preparations (A1 and $A 2$ ), heart $(H)$ and kidney (K), shown in Fig. $1 \mathrm{~A}$, from testes $(\mathrm{T})$ as well as ovaries from rats that had been treated for 2 days with PMS followed by $0(01), 2(02)$ or $7(03)$ days with HCG as previously described [18]; shown in Fig. 1B. In Fig. 1A, the minus RT controls ( - ), in which reverse transcriptase was omitted from the reaction mixture, are also shown. The no-template controls are run in lanes $w$. The marker lane $(M)$ contains DNA size markers of $2176,1766,1230,1033,653,517,453,394,298,234,220$ and 154 bp. Note that the PCR products seen in the kidney lane (Fig. 1A) could not be re-amplified with internal primers, indicating that they are distinct from HL cDNA (not shown).

were apparent, all agreeing to the restriction map of this part of $\mathrm{HL}$ cDNA. Furthermore, re-amplification of the 596-bp DNA from adrenals, ovaries and liver with HL-2 and the internal primer HL-3 generated a product with the predicted size of 552-bp (Fig. 2C). Similar results were obtained with the PCR product from testis RNA (not shown). Taken together, these observations indicate that HL mRNA is expressed in the rat steroidogenic organs, but not in heart and kidney.

Expression of the mRNA for $\mathrm{HL}$ in rat adrenals and ovaries, but not in heart and kidney, coincides with the presence of a liver-type lipase activity in the former 


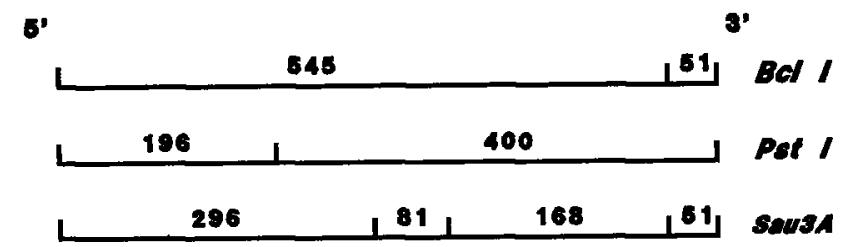

A.

B.
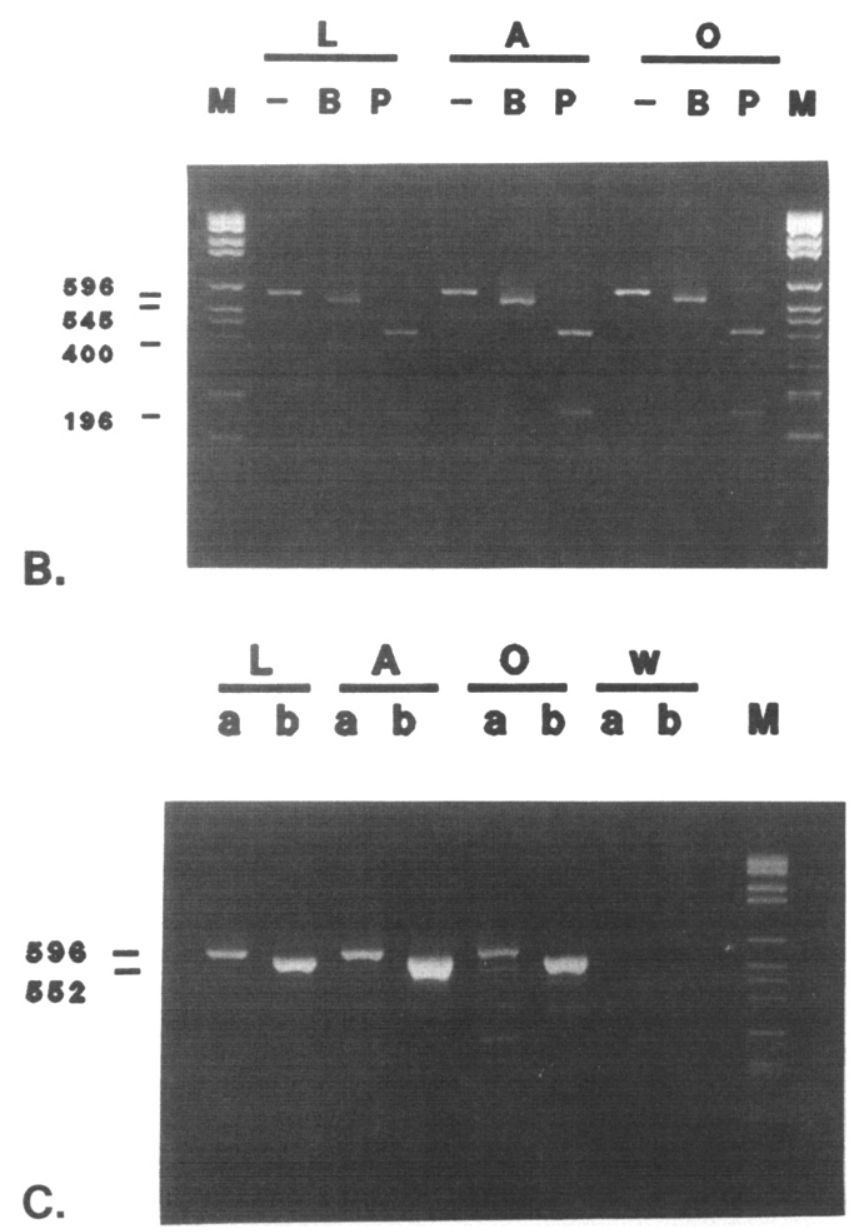

Fig. 2. The 596-bp PCR product is part of the HL cDNA. (A) Partial restriction map of the 596-bp PCR product deduced from the cDNA sequence for rat $\mathrm{HL}$ [14]. The restriction sites for $B c l \mathrm{I}, P s t \mathrm{I}$ and Sau 3A are indicated as well as the predicted restriction fragment lengths. (B) Restriction patterns of the RT-PCR products generated from rat liver (L), adrenal (A) and ovarian (O) RNA. After RT-PCR, the reaction mixtures were incubated without any restriction enzyme $(-)$, or in the presence of $B c l$ I (B) or Pst I (P), and then analyzed by agarose gel electrophoresis. Note that in the experiment shown here ethidiumbromide staining of the expected 51-bp fragment is too low for visualization. The DNA size markers $(M)$ are as defined for Fig. 1. (C) Internal re-amplification. After RT-PCR of rat liver RNA (L), adrenal RNA (A), ovarian RNA (O) and the no-template control (w), the reaction mixtures were diluted $10^{4}$-fold into a fresh PCR mixture. Reamplification was performed either with the original primers IIL-1 and HL-2 (a), or with the combination of HL-2 and the internal primer HL-3 (b). The DNA size markers in lane $M$ are as detailed in the legend to Fig. 1. organs, but not in the latter. In rat testes, however, HL mRNA is present although a similar enzyme activity has not been reported previously. In homogenates prepared from 4 testes, a salt-resistant triglyceridase activity was detected, which amounted to $26.8 \pm 0.3 \mathrm{mU} /$ gww (mean \pm S.D., $n=3$ ). Of this activity, less than $5 \%$ was susceptible to immunoinhibition with polyclonal antibodies against rat liver HL. Upon chromatography on Sepharose-heparin, however, a lipase activity eluted from the column at the same salt-concentration as $\mathrm{HL}$ from rat liver $(0.6-0.7 \mathrm{M} \mathrm{NaCl})$, and which was $80-90 \%$ inhibitable by anti-HL. This activity amounted to $0.20 \pm 0.04 \mathrm{mU} / \mathrm{gww}$. Hence, rat testes also contain a liver-type lipase activity albeit at much lower levels than adrenals and ovaries (40-200 mU/ gww).

Human hyperplastic adrenals have been reported to also contain a liver-type lipase activity [4]. We therefore tested whether HL mRNA is expressed in this tissue as well. Homogenates prepared from the enlarged adrenals of two patients suffering from Cushing's disease contained a salt-resistant lipase activity (Table 1). On a protein basis, this activity was similar in both adrenals of the two patients. A major part of this activity was sensitive to immunoinhibition by anti-human HL. RT-PCR on the RNA preparations of all four adrenals using HL-1 and $\mathrm{HL}-2$ yielded a product of the expected 596-bp (Fig. 3). In the absence of reverse transcriptase, no product was produced. A similar PCR product was also generated with RNA from HepG2 cells (Fig. 3), which synthesize and secrete HL activity into the culture medium, but not with RNA from human endothelial cells. Re-amplification of the PCR product from HepG2 cells and the adrenals from patient 1 using $\mathrm{HL}-2$ and HL-3 resulted in the predicted 552-bp band (not shown). In addition, treatment of the 596-bp product from HepG2 cells and human adrenals with $B c l$ I gave a highly similar digestion pattern which agreed to the restriction map of human HL cDNA (not shown). Pst I was inactive with both PCR products as this restriction site is absent in human opposed to rat HL cDNA [14,20,21]. Hence, HL mRNA and a livertype lipase activity are both present in human hyperplastic adrenals.

Table 1

Lipase activities in adrenal glands of patients with Cushing's disease

\begin{tabular}{|c|c|c|c|c|}
\hline \multirow{2}{*}{\multicolumn{2}{|c|}{ Patient }} & \multicolumn{2}{|c|}{ Lipase activity } & \multirow{2}{*}{$\begin{array}{l}\text { Inhibition by } \\
\text { anti-liver lipase } \\
(\%)\end{array}$} \\
\hline & & $(\mathrm{mU} / \mathrm{gww})^{\mathrm{a}}$ & $(\mathrm{mU} / \mathrm{mg})^{\mathrm{b}}$ & \\
\hline \multirow[t]{2}{*}{1} & left & 23.4 & 0.35 & 68 \\
\hline & right & 22.7 & 0.26 & 65 \\
\hline \multirow[t]{2}{*}{2} & left & 40.8 & 0.34 & 73 \\
\hline & right & 45.8 & 0.40 & 77 \\
\hline
\end{tabular}

${ }^{a}$ Activity expressed per tissue wet weight.

${ }^{b}$ Activity expressed per mg protein. 


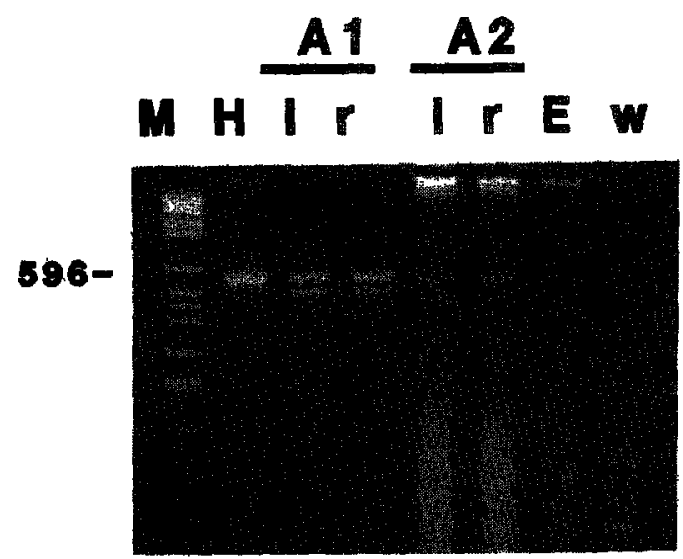

Fig. 3. Detection of HL mRNA in human adrenal glands by RT-PCR. RT-PCR was performed with $1 \mu \mathrm{g}$ of total RNA prepared from HepG2 cells $(H)$, from the left (I) and right ( $r$ ) adrenal of two patients suffering from Cushing's disease (A1 and $\mathrm{A} 2$ ), and from human umbilical vein endothelial cells (E). Other symbols are as defined in Fig. 1.

In conclusion, we have shown here that the $\mathrm{HL}$ gene is transcribed in rat and human steroidogenic organs which also express liver-type lipase activity, but not in organs and tissues which lack such an activity. This finding suggests that the lipase present in these organs may be locally produced. Until now, however, neither we nor others $[12,13]$ have been able to demonstrate $\mathrm{HL}$ protein synthesis in these tissues. Although the RT-PCR data only allow for qualitative conclusions, they seem to indicatc that quantitatively expression of HL mRNA in the rat tissues is at variance with the activity of the livcr-type lipase in these organs. First, the HL mRNA is readily amplified from testis RNA although the activity is at least 2 orders of magnitude less than in adrenals and ovaries. Second, quantitation by competitive RT-PCR shows that the abundance of the HL mRNA in rat adrenals is 40-fold less than in rat liver, although on a wet weight basis both organs contain a similar activity (Verhoeven et al., unpublished data). Therefore, the possibility that the lipase activity in the steroidogenic organs originates from the liver cannot be excluded. Nevertheless, the simultaneous expression of $\mathrm{HL}$ activity and transcription of the HL gene exclusively in cholesterol utilizing tissues forms an intriguing clue to the function and regulation of this enzyme.

We wish to thank Dr. A. Themmen, Department of Endocrinology and Reproduction for supplying us with the RNA from rat ovaries and testes, and Drs. L. Hofland and P. van Koetsveld, Department of Internal Medicine, for the collection of patient material. Part of this study was supported by the Dutch Heart Foundation / Dutch Organization for Scientific Research (grant nr. 900-539-116).

\section{References}

[1] Jansen, H. and Hülsmann, W.C. (1985) Biochem. Soc. Trans. 13, 24-26.

[2] Bamberger, M., Glick, M. and Rothblat, G.H. (1983) J. Lipid Res. 24, 869-876.

[3] Collet, X., Vieu, C., Chap, H. and Perret, B.P. (1991) Biochim. Biophys. Acta 1081, 211-219.

[4] Jansen, H. and Birkenhäger, J.C. (1981) Metabolism 30, 428-430.

[5] Jansen, H. and De Greef, W.J. (1981) Biochem. J. 196, 739-745.

[6] Cordle, S.R., Yeaman, S.J. and Clegg, R.A. (1983) Biochim. Biophys. Acta 753, 213-219.

[7] Gåfvels, M., Bengtsson-Olivecrona, G. and Olivecrona, T. (1989) J. Reprod. Fertil. 86, $589-598$.

[8] Audersen, J.M. and Dietschy, J.M. (1978) J. Biol. Chem. 253, 9024-9032.

[9] Gwynne, J.T. and Strauss, J.F., III (1982) Endocrine Rev. 3 299-329.

[10] Jansen, H., Kalkman, C., Birkenhäger, J.C. and Hülsmann, W.C. (1980) FEBS Lett. 112, 30-34.

[11] Persoon, N.L.M., Sips, H.J., Hülsmann, W.C. and Jansen, H. (1986) Biochim. Biophys. Acta 875, 286-292.

[12] Doolittle, M.H., Wong, H., Davis, R.C. and Schotz, M.C. (1987) J. Lipid Res. 28, 1326-1334.

[13] Hixenbaugh, E.A., Sullivan, T.R., Jr., Strauss, J.F., III, Laposata, E.A., Komaromy, M. and Paavola, L.G. (1989) J. Biol. Chem. 264, 4222-4230.

[14] Komaromy, M.C. and Schotz, M.C. (1987) Proc. Natl. Acad. Sci. USA. 84, 1526-1530.

[15] Semenkovich, C.F., Chen, S.-H., Wims, M., Luo, C.-C., Li, W.-H. and Chan, L. (1989) J..Lipid Res. 30, 423-431.

[16] Peterson, J., Olivecrona, T. and Bengtsson-Olivecrona, G. (1985) Biochim. Biophys. Acta 837, 262-270.

[17] Chomczynski, P. and Sacchi, N. (1987) Anal. Biochem. 162, 156-159.

[18] Jansen, H. and De Greef, W.J. (1988) Mol. Cell. Endocrinol. 57, 7-15.

[19] Sambrook, J., Fritsch, E.F. and Maniatis, T. (1989) Molecular cloning, a laboratory manual (2nd Edit.), Cald Spring Harbor Lab. Press, New York.

[20] Stahnke, G., Sprengel, R., Augustin, J. and Will, II. (1987) Differentiation 35, 45-52.

[21] Martin, G.A., Busch, S.J., Meredith, G.D., Cardin, A.D., Blankenship, D.T., Mao, S.J.T., Rechtin, A.E., Woods, C.W., Racke, M.M., Schafer, M.P., Fitzgerald, M.C., Burke, D.M., Flanagan, M.A and Jackson, R.L. (1988) J. Biol. Chem. 263, 10907-10914.

[22] Ameis, D., Stahnke, G., Kobayashi, J., McLean, J., Lee, G., Büscher, M., Schotz, M.C. and Will, H. (1990) J. Biol. Chem. $265,6552-6555$.

[23] Cai, S.J., Wong, D.M., Chen, S.M. and Chan, L. (1989) Biochemistry 28, 8966-8971.

[24] Lowry, O.H., Rosenbrough, N.J., Farr, A.L. and Randall, R.J (1951) J. Biol. Chem. 193, 265-275. 